\title{
Crescimento do algodoeiro colorido pós-poda em solos com distintas PSTs e doses de esterco
}

\section{Cotton growth colored post-pruning on soil with different PSTs and manure of doses}

\author{
Luana Lucas de Sá Almeida ${ }^{1}$, Reginaldo Gomes Nobre ${ }^{2}$, Leandro de Pádua Souza ${ }^{3}$, Joicy Lima Barbosa ${ }^{4}, J_{\text {Jutahy Jorge Elias }}^{4}$
}

RESUMO: A pesquisa foi conduzida em ambiente protegido no CCTA/UFCG onde objetivou-se avaliar o crescimento de plantas de algodoeiro de fibra naturalmente colorida cv. BRS Topázio, no segundo ciclo produtivo pós-poda, em solos salinosódico sob esterco bovino. Usou-se o delineamento de blocos casualizados em esquema fatorial 5 x 4, com 3 repetições, cujos tratamentos consistiram de cinco percentagens de sódio trocável - PST $(13,6 ; 22,4 ; 30,1 ; 39,0$ e 48,0\%) e quatro doses de esterco bovino $(0 ; 5 ; 10$ e 15\%). Ao encerrar a produção das plantas de algodoeiro (primeiro ciclo) realizou-se uma poda drástica, onde, após as brotações (segundo ciclo) avaliaram-se aos 51 e 91 dias após a poda (DAP) as variáveis: comprimento do ramo (CR), diâmetro do ramo (DR), diâmetro do caule (DC) e número de folhas (NF). Doses de 10\% de matéria orgânica favoreceu o comprimento do ramo e, de $15 \%$ o diâmetro do ramo e do caule de plantas de algodoeiro cv. BRS Topázio aos 51 e 91 dias após a poda. Percentagens de sódio trocável de até $48 \%$ não influenciou o comprimento e o diâmetro de ramos, o diâmetro do caule e o número de folhas do algodoeiro aos 51 e 91 dias após a poda. A interação entre os fatores (PST x MO) promoveu efeito significativo sobre o diâmetro do caule de plantas de algodoeiro aos 91 DAP.

Palavras-chaves: Gossypium hirsutum L., Sódio trocável, adubo orgânico.

SUMMARY: The research was conducted in protected environment in the CCTA / UFCG which aimed to evaluate the growth of naturally colored hp fiber cotton plants. BRS Topaz, the second post-pruning production cycle in saline-sodic soils manure. It used the randomized block design in a factorial $5 \times 4$, with 3 repetitions and the treatments consisted of five percentages of exchangeable sodium - PST $(13.6 ; 22.4 ; 30.1 ; 39.0$ and $48.0 \%)$ and four doses of cattle manure $(0,5,10$ and $15 \%)$. To cease production of cotton plants (first cycle) held a drastic pruning, where, after the shoots (second cycle) were evaluated after 51 and 91 days after pruning (DAP) variables: branch length (CR), branch diameter (DR), stem diameter (DC) and number of leaves (NF). Doses of $10 \%$ organic matter favored branch length and $15 \%$ of the diameter of the branch and cotton plants $\mathrm{cv}$ stem. BRS Topaz after 51 and 91 days after pruning. Exchangeable sodium in percentages of up to $48 \%$ did not influence the length and diameter of branches, the stem diameter and the number of cotton leaves at 51 and 91 days after pruning. The interaction between the factors (PST x MO) has promoted significant effect on stem diameter of cotton plants at 91 DAP.

Keywords: Gossypium hirsutum L., exchangeable sodium, organic fertilizer.

\footnotetext{
*Autor para correspondência

Recebido para publicação em 29/08/2015; aprovado em 20/09/2015

${ }^{1}$ Eng. Agrônoma, Pós-graduanda em Horticultura Tropical, Centro de Ciências e Tecnologia Agroalimentar, Universidade Federal de Campina Grande, CEP 58015-570 Pombal, PB, Fone (83) 999429453. E-mail: luana_lucas_15@hotmail.com,

${ }^{2}$ Prof. Doutor Adjunto III CCTA/ UAGRA/UFCG, Pombal, PB. E-mail: rgomesnobre@pq.cnpq.br;

${ }^{3}$ Eng. Agrônomo, Mestrando em Horticultura Tropical, UFCG, Pombal, PB. E-mail: engenheiropadua @ hotmail.com;

${ }^{4}$ Graduando em Agronomia, CCTA/UFCG, Pombal, PB. E-mails: joicy.barbosa0@ gmail.com; Jutahy.jorge33@gmail.com;
} 


\section{INTRODUÇÃO}

O algodão de fibra naturalmente colorida vem despertando interesse dos produtores e consumidores no Brasil e no mundo, tendo em vista ser um mercado crescente, com grande potencial socioeconômico para fixação de mão de obra, geração de empregos e fonte de matéria-prima para a indústria têxtil (CARDOSO, 2009; SILVA et al., 2014).

Através de programas de melhoramento genético desenvolvido pela EMBRAPA, várias variedades de algodoeiro de fibra colorida têm surgido com qualidade semelhante ou superior às de fibra branco, sendo considerada uma cultura tolerante a estresses hídrico e salino (DANIEL et al., 2011). Além disso, o algodoeiro de fibra naturalmente colorida também detém grande importância ambiental, uma vez que elimina a fase de tingimento na indústria, que tem lançado grande quantidade de resíduos no ambiente (CARDOSO et al., 2010).

A salinidade e/ou sodicidade é um problema que gera grande preocupação aos produtores de regiões áridas e semiáridas do Brasil e do mundo, tendo em vista que, o excesso de sais no solo exerce efeitos adversos tanto em plantas, incluindo distúrbios osmóticos, que dificulta a absorção de água pelas raízes, toxicidade por íons e desequilíbrio nutritivo, quanto nos solos, tornando-os impermeáveis e de difícil manejo (RIBEIRO et al., 2010; SÁ et al., 2015).

Parte deste desequilíbrio químico que alguns solos do Nordeste brasileiro possuem é consequência do manejo inadequado da irrigação, que se faz necessária para que se obtenha uma maior produtividade; visto que, se trata de uma região com altas taxas de evaporação e baixa precipitação, que quando associadas às características do material de origem e às condições geomorfológicas e hidrológicas, condicionam a formação de solos com teores elevados de sais solúveis e sódio trocável (GOMES et al., 2000).

A redução do grau de salinidade envolve o processo de solubilização e a consequente remoção pela água de percolação, enquanto a diminuição do teor de sódio trocável envolve o seu deslocamento do complexo de troca pelo cálcio e posteriormente a realização de lixiviação (BARROS et al., 2004).

Assim sendo, para que esses solos afetados por sais possam voltar a ser produtivos, precisam passar por um processo de recuperação, que tem como objetivo a redução da concentração dos sais solúveis e do sódio trocável no perfil do solo. Para tanto, usa-se melhoradores químico ou orgânico, sendo os mais usados, o esterco bovino e gesso agrícola, devido a sua grande disponibilidade no mercado e baixo custo, estando acessível para os pequenos, médios e grandes produtores (MIRANDA et al., 2011; VITAL et al., 2005).

Pelo exposto, objetivou-se com esta pesquisa, avaliar o crescimento de plantas de algodoeiro de fibra naturalmente colorida, cv. BRS Topázio, no segundo ciclo pós-poda, em solos salino-sódico sob doses de esterco bovino.

\section{MATERIAL E MÉTODOS}

A pesquisa foi desenvolvida em condição de casa de vegetação (ambiente protegido) pertencente ao Centro de Ciências e Tecnologia Agroalimentar (CCTA) da Universidade Federal de Campina Grande (UFCG), Pombal,
PB, cujas coordenadas geográficas são $6^{\circ} 47^{\prime} 20^{\prime \prime}$ S, $37^{\circ} 48^{\prime} 01$ '" W e altitude média de $194 \mathrm{~m}$.

O material de solo utilizado no experimento foi coletado na profundidade de 0-30 cm, de uma área localizada no perímetro irrigado de São Gonçalo, Sousa-PB, cujas características físicas e químicas encontram-se na Tabela 1.

$\mathrm{O}$ experimento foi realizado em delineamento em blocos inteiramente casualizado, analisados em esquema fatorial $5 \times 4$, com três repetições e uma planta por parcela sendo, os tratamentos compostos por solos com distintas percentagens de sódio trocável sendo estas, PST - 13,6; 22,4; 30,1; 39,0 e 48,0\% associado ao fator doses de esterco, sendo $0 ; 5 ; 10$ e $15 \%$ em base do volume de solo no vaso (12 L); totalizando 60 unidades experimentais.

Utilizou-se como material vegetal o algodoeiro de fibra naturalmente colorida, cv. BRS Topázio, onde segundo Embrapa (2011) são plantas com altura média de $116 \mathrm{~cm}$, fibra de coloração marrom claro, com alto rendimento de fibra (43,5\% em média), alta uniformidade $(85,2 \%)$ e elevada resistência (31,9 gf/tex), conferindo excelentes características, comparável às cultivares de fibras branca e superior às demais de fibras coloridas. Outrossim, a produtividade média sob condição de irrigação é de $2.825 \mathrm{~kg} \mathrm{ha}^{-1}$.

Antecedendo a semeadura do algodoeiro de fibra colorida, o material de solo foi submetido ao tratamento utilizando gesso, com o intuito de obter solos com distintas PST de acordo com os tratamentos. O solo salino-sódico foi destorroado, peneirado e misturado com quantidades de gesso pré-definidas (em base de pré-ensaio) conforme Equação 1 de Pizarro (1985). Depois de realizada a incorporação do gesso ao solo, visando obter os cinco tratamentos de PST, o material de solo foi colocado em cinco recipientes de $200 \mathrm{~L}$ de capacidade, e mantida por 40 dias, com umidade próxima a capacidade de campo, de forma a acelerar a solubilização do gesso e a substituição do sódio do complexo de troca pelo cálcio, e posterior lixiviação a partir de lavagem.

$\mathrm{Dg}=[($ PSTi - PSTf $) \times$ CTC $\times$ PE $\times$ h x Ds $] / 100$

Eq.1

em que:

Dg: Dose teórica de corretivo, $\mathrm{kg} \mathrm{ha}^{-1}$;

PSTi: percentagem de sódio trocável inicial, \%;

PSTf: percentagem de sódio trocável final desejada, \%;

CTC: capacidade de troca de cátions do solo;

PE: peso equivalente do elemento ou composto usado como corretivo;

h: profundidade do solo a ser recuperado $(\mathrm{cm})$; Ds: densidade global do solo, $\mathrm{g} \mathrm{cm}^{-3}$.

Ao final do período de lixiviação, o material de solo foi seco ao ar, destorroado e passado em peneira com malha de 2 $\mathrm{mm}$, em seguida, as amostras foram encaminhadas para o Laboratório de Solos e Nutrição de Plantas do CCTA/UFCG para determinação dos percentuais de sódio trocável. Os resultados da análise indicaram PST do solo 13,6; 22,4; 30,1; 39,0 e $48,0 \%$ e CEes de 3,$75 ; 5,61 ; 7,09 ; 8,66$ e $10,12 \mathrm{dS} \mathrm{m}^{-1}$, respectivamente.

Usou-se para condução das plantas, lisímetros de drenagem com $12 \mathrm{~L}$ de capacidade, preenchidos com $1 \mathrm{~kg}$ de brita ( $\mathrm{n}^{\mathrm{o}}$ zero) seguido de $1 \mathrm{~kg}$ areia a qual cobri a base do lisímetro, visando favorecer a drenagem; na sequência foram colocados $10 \mathrm{~kg}$ do material de solo (distintas PST conforme tratamentos) e as distintas doses de esterco bovino curtido. $\mathrm{O}$ 
esterco foi misturado ao solo na camada superior (1/3). Cada lisímetro possuía um orifícios em sua base permitindo a drenagem e, abaixo deles, um microtubo (1 cm de diâmetro) conectando sua base uma garrafa plástica ( $2 \mathrm{~L}$ de capacidade) onde é feito o acompanhamento do volume drenado, estimativa do consumo de água pela cultura e determinação da $\mathrm{CE}$ e $\mathrm{pH}$ da água de drenagem.

As unidades experimentais foram dispostas em fileira simples espaçadas de $0,6 \mathrm{~m}$ entre fileiras e $0,4 \mathrm{~m}$ entre plantas dentro da fileira.

A água utilizada na irrigação era de baixa condutividade elétrica $\left(\mathrm{CEa}=0,3 \mathrm{dS} \mathrm{m}^{-1}\right)$ sendo as irrigações realizadas diariamente às $17 \mathrm{~h}$ de acordo com a necessidade hídrica das plantas, acrescido de fração de lixiviação (FL) média de $10 \%$. As plantas foram mantidas sob solo a capacidade de campo com irrigações diárias, mensuradas pelo consumo de água obtido pelo balanço hídrico.

A semeadura foi realizada utilizando oito sementes por vaso a $0,02 \mathrm{~m}$ de profundidade e distribuídas de forma equidistante, posteriormente fez-se o desbaste, deixando a mais vigorosa.

O controle fitossanitário foi realizado com a utilização de acaricida, realizadas no período da tarde, como forma de amenizar a ocorrência de morte de insetos polinizadores, quando da aplicação dos agroquímicos.

Realizou-se capinas, quando necessário para controlar a incidência de plantas invasoras, nociva à cultura de interesse.
Após o período de produção do primeiro ciclo da cultura, setembro de 2014, foi realizada uma poda drástica em cada planta, deixando o caule de cada planta com $10 \mathrm{~cm}$ de altura. Estas foram tratadas com calda bordalesa, para prevenção de doenças fungicas e cada planta foi mantida com 3 a 4 gemas brotadas e conduzidas até a fase de produção. Iniciando-se o segundo ciclo da cultura que se estendeu até dezembro de 2014 encerrando com a produção das plantas.

$\mathrm{Na}$ avaliação dos efeitos dos distintos tratamentos sobre o cultivo do algodoeiro cv. BRS Topázio, foram avaliados, comprimento médio de ramos (CR), diâmetro médio de ramos (DR), diâmetro do caule (DC) e número de folhas (NF) aos 51 e 91 dias após a poda (DAP).

Estimou-se o CR por meio de uma régua graduada, adotando-se a distância entre a base do ramo da planta ao ápice, onde esta foi mensurada em $\mathrm{cm}$.

$\mathrm{O}$ DC e DR foi determinado com um paquímetro digital, verificando-se, o colo da planta e a base do ramo respectivamente, a $3 \mathrm{~cm}$ de distancia tanto do solo quando do ponto de inserção do ramo, sendo medidos em mm.

$\mathrm{Na}$ contagem das folhas, foram consideradas apenas folhas com comprimento superior a $2 \mathrm{~cm}$, e que tinham mais de $50 \%$ de sua área fotossinteticamente ativa.

As variáveis de crescimento, foram submetidas à análise de variância, com Teste F (1 e 5\% de probabilidade) e nos casos significativos, realizou-se estudos de regressão polinomial utilizando o software estatístico SISVAR.

Tabela 1. Características físicas e químicas do solo utilizado no experimento, antes da aplicação dos tratamentos.

\begin{tabular}{|c|c|c|c|c|c|c|c|c|c|c|c|}
\hline \multirow{2}{*}{ Densidade } & \multirow{2}{*}{$\begin{array}{l}\text { Porosidade } \\
\text { Total }\end{array}$} & \multirow{2}{*}{ Areia } & \multirow{2}{*}{ Silte } & \multirow{2}{*}{ Argila } & \multicolumn{4}{|c|}{ Complexo Sortivo } & \multirow{2}{*}{ PST } & \multirow{2}{*}{$\mathrm{pH}_{\mathrm{ps}}$} & \multirow{2}{*}{$\mathrm{CE}_{\mathrm{es}}$} \\
\hline & & & & & $\mathrm{Ca}^{+2}$ & $\mathrm{Mg}^{+2}$ & $\mathrm{Na}^{+}$ & $\mathrm{K}^{+}$ & & & \\
\hline $\mathrm{kg} \mathrm{dm}^{-3}$ & $\mathrm{~m}^{3} \mathrm{~m}^{-3}$ & \multicolumn{3}{|c|}{$\ldots \ldots \ldots . . . \mathrm{g} \mathrm{kg}^{-1}$} & \multicolumn{4}{|c|}{$\ldots \ldots \ldots \ldots . . \mathrm{cmol}_{\mathrm{c}} \mathrm{kg}^{-1}$} & $\%$ & - & $\mathrm{dS} \mathrm{m} \mathrm{m}^{-1}$ \\
\hline 1,32 & 0,52 & 729 & 131 & 140 & 1,74 & 0,42 & 25,44 & 0,71 & 89,95 & 9,62 & 45,20 \\
\hline
\end{tabular}

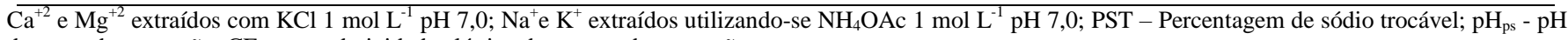
da pasta de saturação; CEes - condutividade elétrica do extrato de saturação.

\section{RESULTADOS E DISCUSSÃO}

De acordo com a análise de variância (Tabela 2) não se observa efeito significativo do fator PST e da a interação entre os fatores (PST x MO) em nenhuma das épocas avaliadas sobre o comprimento e o diâmetro do ramo do algodoeiro porém, nota-se o oposto para o fator matéria orgânica, na qual se obteve significância $(\mathrm{p} \leq 0,05)$ para o $\mathrm{CR}$ e o DR aos 51 e 91 DAP.

Tabela 2 - Resumos das análises de variâncias para comprimento (CR) e diâmetro do ramo (DR) aos 51 e 91 DAP do algodoeiro cv. BRS Topázio cultivado em solo com distintas percentagens de sódio trocáveis e níveis de esterco bovino.

\begin{tabular}{|c|c|c|c|c|}
\hline \multirow{3}{*}{ TRATAMENTOS } & \multicolumn{2}{|c|}{$\mathrm{CR}$} & \multicolumn{2}{|c|}{ DR } \\
\hline & $51 \mathrm{DAP}$ & 91 DAP & $51 \mathrm{DAP}$ & 91 DAP \\
\hline & \multicolumn{4}{|c|}{ Quadrados Médios } \\
\hline Percentagem de sódio trocável (PST) & $4,768^{\mathrm{ns}}$ & $24,187^{\mathrm{ns}}$ & $0,500^{\mathrm{ns}}$ & $0,394^{\mathrm{ns}}$ \\
\hline Reg. Linear & $1,852^{\mathrm{ns}}$ & $2,803^{\mathrm{ns}}$ & $0,008^{\mathrm{ns}}$ & $0,152^{\mathrm{ns}}$ \\
\hline Reg. Quadrática & $6,188^{\mathrm{ns}}$ & $22,999^{\mathrm{ns}}$ & $0,449^{\mathrm{ns}}$ & $0,327^{\mathrm{ns}}$ \\
\hline Matéria orgânica(MO) & $386,164^{*}$ & $272,481^{*}$ & $4,247^{*}$ & $2,786^{*}$ \\
\hline Reg. Linear & $803,014^{*}$ & $461,875^{*}$ & $9,821^{*}$ & $6.351^{*}$ \\
\hline Reg. Quadrática & $330,974^{*}$ & $251,986^{*}$ & $2,834^{*}$ & $1.983^{*}$ \\
\hline Interação PST x MO & $33,915^{\mathrm{ns}}$ & $34,582^{\mathrm{ns}}$ & $0,220^{\mathrm{ns}}$ & $0,245^{\mathrm{ns}}$ \\
\hline Bloco & $387,548^{*}$ & $385,636^{*}$ & $0,700^{\mathrm{ns}}$ & $1.487^{*}$ \\
\hline $\mathrm{CV}(\%)$ & 17.35 & 12,57 & 11,03 & 9.29 \\
\hline
\end{tabular}

$\mathrm{ns}, * *$ * respectivamente não significativo, significativo a $\mathrm{p}<0,01$ e $\mathrm{p}<0,05$ 
Conforme a equação de regressão referente á variável comprimento de ramo aos 51 e 91 DAP (Figura 1A e 1B, respectivamente), o modelo ao qual os dados se ajustaram melhor foi o quadrático, notando-se acréscimo no comprimento de ramo até um percentual de $10 \%$ de MO, obtendo os maiores valores de CR de 35,05 e 36,08 cm aos 51 e 91 DAP, respectivamente. Denota-se que o acréscimo no fornecimento de material orgânico até a dose de $10 \%$ tenha proporcionado condições favoráveis para o desenvolvimento das raízes, tornando o ambiente com melhores características físicas, químicas e biológicas (FAVALESSA, 2011), sendo essa técnica economicamente viável pois aumenta o crescimento e produtividade das plantas (SILVA et al., 2012). Porém, possivelmente, os elevados teores de esterco tenham promovido desbalanço nutricional no solo e, em consequência, a redução no crescimento da cultura (NOBRE et al., 2010).

Figura 1: Comprimento de ramo (CR) do algodoeiro cv. BRS Topázio em função das doses de matéria orgânica (MO) aos 51 (A) e 91 (B) dias após a poda (DAP).
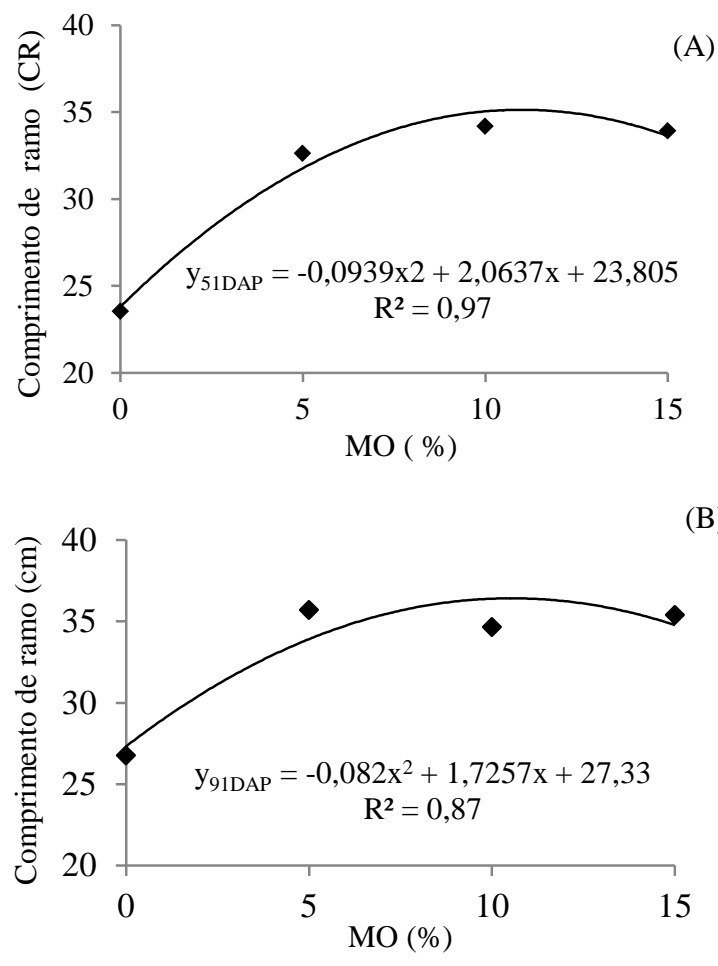

O Diâmetro do ramo aos 51 e 91 DAP (Figura 2) foi influenciado significativamente $(\mathrm{p} \leq 0,05)$ pelo incremento da MO, onde aos 51 DAP observa-se um comportamento quadrático, verificando-se um maior diâmetro $(12,97 \mathrm{~mm})$ quando as plantas estavam adubadas com $15 \%$ de esterco bovino e segundo a equação de regressão, o modelo linear do DC aos 91 DAP indica um aumento de 0,99\% com incremento unitário da $\mathrm{MO}$, sendo equivale a um aumento de
1,42 mm em relação a menor dose de esterco bovino. Esta resultância certamente é devido a melhor estruturação do solo, causada pela matéria orgânica e a influencia do nitrogênio, que desempenha uma função vital a planta, visto que o esse nutriente o algodoeiro retira do solo em maior proporção (SILVA et al., 2008). Outrossim, a incorporação de estercos em solos aumenta os teores de matéria orgânica, proporcionando maior capacidade de armazenamento e disponibilidade de água as plantas, bem como a aeração do solo e o desenvolvimento das raízes (OLIVEIRA et al., 2015), melhorando, dessa forma, a estruturação do solo salino-sódio, que por sua vez são desestruturados e impermeáveis (SILVA et al., 2014).

Figura 2: Diâmetro de ramo (DR) do algodoeiro cv. BRS Topázio em função das doses de matéria orgânica (MO) aos 51 e 91 DAP

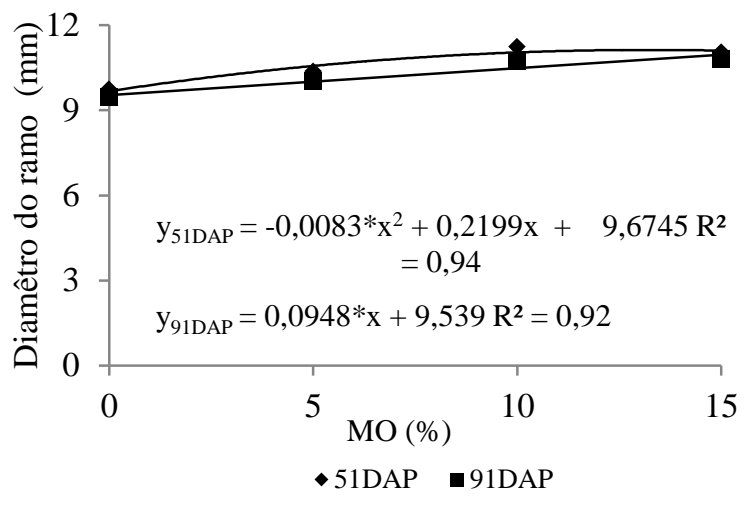

Conforme os resultados da análise de variância (Tabela 3) houve efeito significativo $(p \leq 0,01)$ da interação entre os fatores (percentagem de sódio trocável e níveis de matéria orgânica) para a variável, diâmetro do caule aos 91 DAP. Para o fator MO houve efeito significativo $(\mathrm{p} \leq 0,05)$ apenas para o diâmetro do caule aos 51 DAP. Tratando-se do número de folhas não houve significância para nenhum dos fatores em nenhuma das épocas estudadas.

O diâmetro do caule aos 51 DAP (Figura 3) apresentou resposta linear crescente ao incremento das percentagens de matéria orgânica, ou seja, o aumento unitário dos percentuais de esterco bovino proporcionou acréscimo de $0,96 \%$ no diâmetro do ramo do algodoeiro, ocorrendo DR de 11,31 mm sob adubação de $15 \%$ de MO. Comprova-se com este resultado, a grande influência da matéria orgânica para que se tenha uma produção satisfatória da cultura, tendo em vista que, a utilização de esterco bovino pode contribuir para melhorar a tolerância das plantas aos sais, e proporcionar uma melhor estruturação do solo, melhor drenagem e maior disponibilidade de nutrientes, respeitando as limitações de dosagem (SOUTO et al., 2015). 
Tabela 3 - Resumos das análises de variâncias para diâmetro do caule (DC) e numero de folhas (NF) do algodoeiro cv. BRS Topázio aos 51 e 91 DAP cultivado em solo com distintas percentagens de sódio trocáveis e níveis de esterco bovino.

\begin{tabular}{|c|c|c|c|c|}
\hline \multirow{3}{*}{ TRATAMENTOS } & \multicolumn{2}{|c|}{$\mathrm{DC}$} & \multicolumn{2}{|c|}{ NF } \\
\hline & $51 \mathrm{DAP}$ & 91 DAP & 51 DAP & 91 DAP \\
\hline & \multicolumn{4}{|c|}{ Quadrados Médios } \\
\hline Percentagem de sódio trocável (PST) & $0,531^{\mathrm{ns}}$ & $0,747^{\mathrm{ns}}$ & $25,766^{\mathrm{ns}}$ & $75,608^{\mathrm{ns}}$ \\
\hline Reg. Linear & $1,408^{\mathrm{ns}}$ & $2,700^{\mathrm{ns}}$ & $24,300^{\mathrm{ns}}$ & $78,408^{\mathrm{ns}}$ \\
\hline Reg. Quadrática & $0,024^{\mathrm{ns}}$ & $0,160^{\mathrm{ns}}$ & $48,214^{\mathrm{ns}}$ & $87,140^{\mathrm{ns}}$ \\
\hline Matéria orgânica(MO) & $6,971^{*}$ & $5,903^{*}$ & $53,888^{\mathrm{ns}}$ & $105,127^{\mathrm{ns}}$ \\
\hline Reg. Linear & $17,041^{*}$ & $15,916^{*}$ & $59,853^{\mathrm{ns}}$ & $39,603^{\mathrm{ns}}$ \\
\hline Reg. Quadrática & $2,604^{*}$ & $1,204^{\mathrm{ns}}$ & $60,000^{\mathrm{ns}}$ & $104,016^{\mathrm{ns}}$ \\
\hline Interação PST x MO & $0,450^{\mathrm{ns}}$ & $0,734^{* *}$ & $89,666^{\mathrm{ns}}$ & $69,863^{\mathrm{ns}}$ \\
\hline Bloco & $1,326^{* *}$ & $0,298^{\mathrm{ns}}$ & $1,800^{\mathrm{ns}}$ & $4,850^{\mathrm{ns}}$ \\
\hline $\mathrm{CV}(\%)$ & 6,19 & 5,84 & 21,22 & 18,07 \\
\hline
\end{tabular}

$\mathrm{ns}, * *$ * respectivamente não significativo, significativo a $\mathrm{p}<0,01$ e $\mathrm{p}<0,05$

Figura 3: Diâmetro do caule do algodoeiro cv. BRS Topázio em função de doses de matéria orgânica (MO) aos 51 DAP.

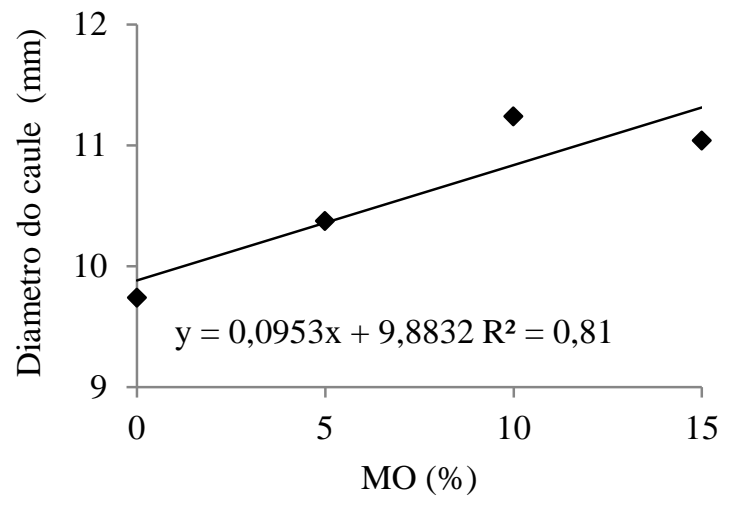

De acordo com a equação de regressão (Figura 4) referente ao diâmetro do caule aos 91 DAP, verifica-se que o aumento dos níveis de esterco bovino proporcionou efeito quadrático, alcançando os maiores diâmetros $(9,97 ; 10,92$; 10,96 e 11,57), nos níveis estimados de 0, 5, 10 e $15 \%$ de MO. Vê-se que a utilização das maiores dose de matéria orgânica (10 e 15\%) em solo salino-sódico ocasionou efeito positivo, pois houve produção adequada do DC mesmo no nível mais alto de PST (48\%). Mais uma vez pode-se notar a grande contribuição que a matéria orgânica traz para cultivos em solos degradados por sais, sendo, de certo modo, a sua utilização necessária para que se tenha uma elevação na produção, fazendo com que solos com limitações químicas tornem-se produtivos, devido aos inúmeros benefícios que a adução orgânica traz as condições físicas do solo e o suprimento das necessidades das plantas em macro e micronutrientes, induzidos pela composição química desse insumo (MALAVOLTA, 2006), sendo uma alternativa para minimizar os efeitos deletérios, tornando as culturas mais resistentes aos ambientes de estresse salino.
Figura 4: Diâmetro do caule (DC) de planta de algodoeiro cv. BRS Topázio, em função da interação entre percentagens de sódio trocável - PST e níveis de esterco bovino aos 91 DAP.

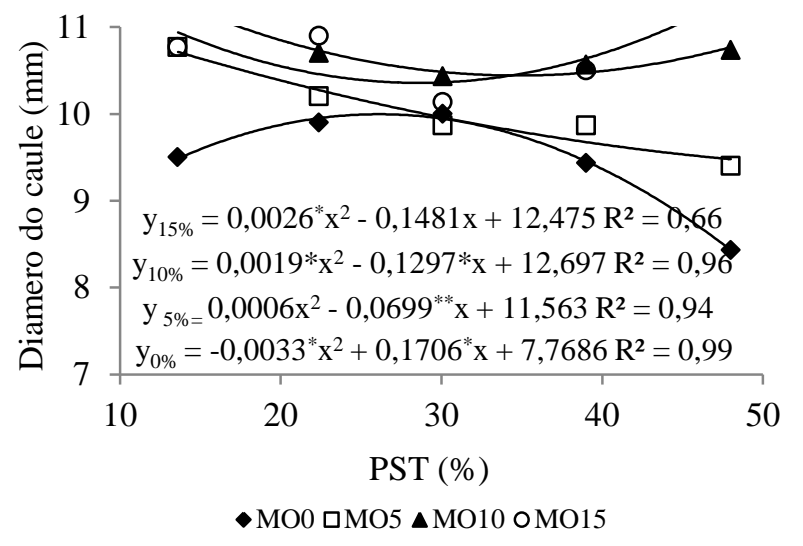

Não se constatou efeito significativo das distintas PST sobre o NF, cujas plantas possuíam número médio de folhas de 37 (51 DAP) e 36 (91 DAP). No primeiro ciclo, Costa (2014) obteve maior número de folhas $(13,6)$ aos 44 dias após o semeio em plantas sob PST de $29 \%$, ou seja, denota-se que após a poda as plantas produziram maior tolerância ao sódio trocável.

É possível, que em função do tempo de condução das plantas, ao longo dos dois ciclos produtivos, que a PST dos distintos solos tenham sido reduzida, devido a lixiviação dos sais, contribuindo para que não se verificasse efeito sobre as distintas variáveis analisadas neste experimento.

\section{CONCLUSÕES}

Doses de $10 \%$ de matéria orgânica favoreceu o comprimento do ramo e, de $15 \%$ o diâmetro do ramo e do caule de plantas de algodoeiro cv. BRS Topázio aos 51 e 91 dias após a poda.

Percentagens de sódio trocável de até $48 \%$ não influenciou o comprimento e o diâmetro de ramos, o diâmetro do caule e o número de folhas do algodoeiro aos 51 e 91 dias após a poda.

A interação entre os fatores (PST x MO) promoveu efeito significativo sobre o diâmetro do caule de plantas de algodoeiro aos 91 DAP. 


\section{REFERÊNCIAS BIBLIOGRÁFICAS}

BARROS, M. DE F. C.; FONTES, M. P. F.; ALVAREZ, V. H.; RUIZ, H. A. Recuperação de solos afetados por sais pela aplicação de gesso de jazida e calcário do Nordeste do Brasil. Campina Grande, Revista Brasileira de Engenharia Agrícola e Ambiental, v.8, n.1, 2004. 59$64 \mathrm{p}$.

CARDOSO, G. D. Períodos de interferência de plantas daninhas em Algodoeiro cultivares BRS safira e BRS verde. São Paulo, Faculdade de ciências agrárias e veterinárias-Câmpus de Jaboticabal, 2009. 60p (Tese de Doutorado).

CARDOSO, G. D.;ALVES, P. L. da C. A.;BELTRÃO, N. E.

de M.;VALE, L. S. do. Períodos de interferência das plantas daninhas em algodoeiro de fibra colorida BRS Safira. Revista Ciência Agronômica (UFC. Impresso), v. 41, p. 456-462, 2010.

COSTA, M. M. L. da. Crescimento do algodoeiro colorido cultivado em solos salino-sódico e doses de matéria orgânica. Pombal, Universidade Federal de Campina Grande, 2014. (Monografia graduação em Agronomia).

DANIEL, V. C. Revista em Agronegócios e Meio Ambiente, v.4, n.2, p. 321-333. 2011 - ISSN 1981-9951

EMBRAPA. Centro Nacional de Pesquisa de Algodão (Campina Grande, PB). Algodão Colorido: “Tecnologia Embrapa para a geração de emprego e renda na agricultura familiar do Brasil', Campina Grande, 2011. 2p. (EMBRAPA-CNPA, Circular Técnico,17).

FAVALESSA. M. Substratos renováveis e não renováveis na produção de mudas de Acacia mangium. Jerônimo Monteiro Espírito Santo, Centro de Ciências Agrárias UFES, 2011. (Monografia Engenharia Florestal).

GOMES, E. M., GHEYI, H. R., SILVA, E. F. F. Melhorias nas propriedades químicas de um solo salino-sódico e rendimento de arroz sob diferentes tratamentos. Revista Brasileira de Engenharia Agrícola e Ambiental, v.4, n.3, p.355-361, 2000 .

MALAVOLTA, E. Manual de nutrição mineral de plantas. São Paulo: Ceres, 2006. 638p.

MIRANDA, M. A.; OLIVEIRA, E. E. M. de; SANTOS, K. C. F. dos. Condicionadores químicos e orgânicos na recuperação de solo salino-sódico em casa de vegetação. Revista Brasileira de Engenharia Agrícola e Ambiental, Campina Grande, v. 15, n. 5, 2011. p.484490

NOBRE, R. G.; GHEYI, H. R.; SOARES, F. A. L.; Produção do girassol sob diferentes lâminas com efluentes domésticos e adubação orgânica. Campina Grande, Revista Brasileira Engenharia Agrícola e Ambiental, 2010. v.14 n.7
OLIVEIRA, F. S. DE; FARIAS, O. R. DE1 NOBRE, R. G. Produção de mudas de mamoeiro "Formosa" com diferentes doses de esterco ovino. Revista Ciências Agrárias, v. 58, n. 1, 2015.p. 52-57.

PIZZARO, F. Drenaje agrícola y recuperacion de suelos salinos. 2 ed. Madrid: Editora Agrícola Española S/A, 1985. 541p. regional and country levels. Rome: FAO, 2000. (FAO. World Soil Resources Report, 90).

RIBEIRO, M.R. Manejo da Salinidade na Agricultura: Estudos Básicos e Aplicados. Fortaleza: Origem e classificação dos solos afetados por sais, 2010.p. 1-9.

SÁ, F. V. DA S.; MESQUITA, E. F. DE; BERTINO, A. M. P.; Influência do gesso e biofertilizante nos atributos químicos de um solo salino-sódico e no crescimento inicial do girassol. Botucatu. Revista Irriga, v. 20, n. 1, 2015. p. 46-59.

SILVA, A. B. F.; FERNANDES, P. D.; GHEYI.; BLANCO, F. F. Growth and yield of guava irrigated with saline water and addition of farmyard manure. Revista Brasileira de Ciências Agrárias, v.3, n. 4, p. 354-359, 2008.

SILVA, J. A. DA, OLIVEIRA, A. P. DE, ALVES, G. DA S. Rendimento do inhame adubado com esterco bovino e biofertilizante no solo e na folha. Campina Grande, Revista Brasileira de Engenharia Agrícola e Ambiental. v.16, n.3, 2012. p.253-257.

SILVA, J. N.; crescimento e produção do algodoeiro colorido em função de diferentes doses e tipos de biofertilizantes; Catolé do Rocha - Curso de Ciências Agrárias, Universidade Estadual da Paraíba, 2014. 45 f. (Monografia Especialização)

SILVA, N. M. L. DA; BARROS, M. DE F. C.; FONTENELE A. J. P.B.; application of gypsum requirement levels and water depth for correction the sodicity and salinity of saline-sodic soils. Revista Brasileira de Agricultura Irrigada v.8, $\mathrm{n}^{\circ} .2$ 2, 2014.p. $147-153$.

SOUSA, G. G. DE, AZEVEDO, B. M. DE, ALBUQUERQUE, A. H. P.; Características agronômicas do amendoinzeiro sob irrigação com águas salinas em solo com biofertilizantes; Revista Agro@mbiente On-line, v. 6, n. 2, p. 124-132, maioagosto, 2012.

SOUTO, A. G. L.; CAVALCANTE, L. F.; DINIZ, B. L. M. T. Água salina e biofertilizante bovino na produção de frutos e alocação de biomassa em noni (Morindak citrifolia L.) Revista Brasileira de Plantas Medicinais, vol.17, n.2, 2015.

VITAL, A. de F. M.; SANTOS, R. V. dos; CAVALCANTE, L. F. Comportamento de atributos químicos de um solo salino-sódico tratado com gesso e fósforo. Revista Brasileira de Engenharia Agrícola e Ambiental, Campina Grande, v. 9, n. 1, p.1807-1812, 2005. 